\title{
No favour, no friends: parsing the qualifications for a journal's editor-in-chief
}

$\mathrm{T}$ here will probably never be a reality television show called Who Wants To Be The Editor Of A Medical Journal? First, the title is too long, even in acronym form (WWTBTEOAMJ). Second, television viewers prefer shows on which competitors sing or dance, and academic physicians aren't known for their pipes or mambo skills. The main reason WWTBTEOAMJ is a bad idea, though, is that worthy contestants would be too hard to find.

Editing a major general medical journal is no easy task. To succeed, a person must be open-minded and innovative, intelligent and media savvy, patient and thick-skinned. Finding someone with the requisite skills and knowledge can be challenging, as a search team at CMAJ will soon discover, having been assigned to find a replacement for the journal's current editor-in-chief, Dr. Paul Hébert, who will be leaving his position sometime this year (www.cmaj.ca/cgi/doi/10.1503 /cmaj.109-3769).

"An editor is a leader," says Dr. Richard Smith, former BMJ editor-inchief. "There are two things that a leader needs. The first is vision. What is it that we are trying to do here? Leaders don't have to set the agenda entirely by themselves but are responsible for making sure there is some kind of vision - more than just getting the journal out every week and just ticking along. Secondly, they need an ability to inspire people with that vision and get them pointed in the same direction."

Successful editors implement their visions and give their journals unique voices, while maintaining a sense of impartiality. Former New England Journal of Medicine editor-in-chief Dr. Jerome Kassirer once wrote that striking this balance is difficult ( $N$ Engl $J$ Med 1999;340:1671-2): "Medical journal editors walk a fine line. They must aspire to impartiality, open-mindedness,

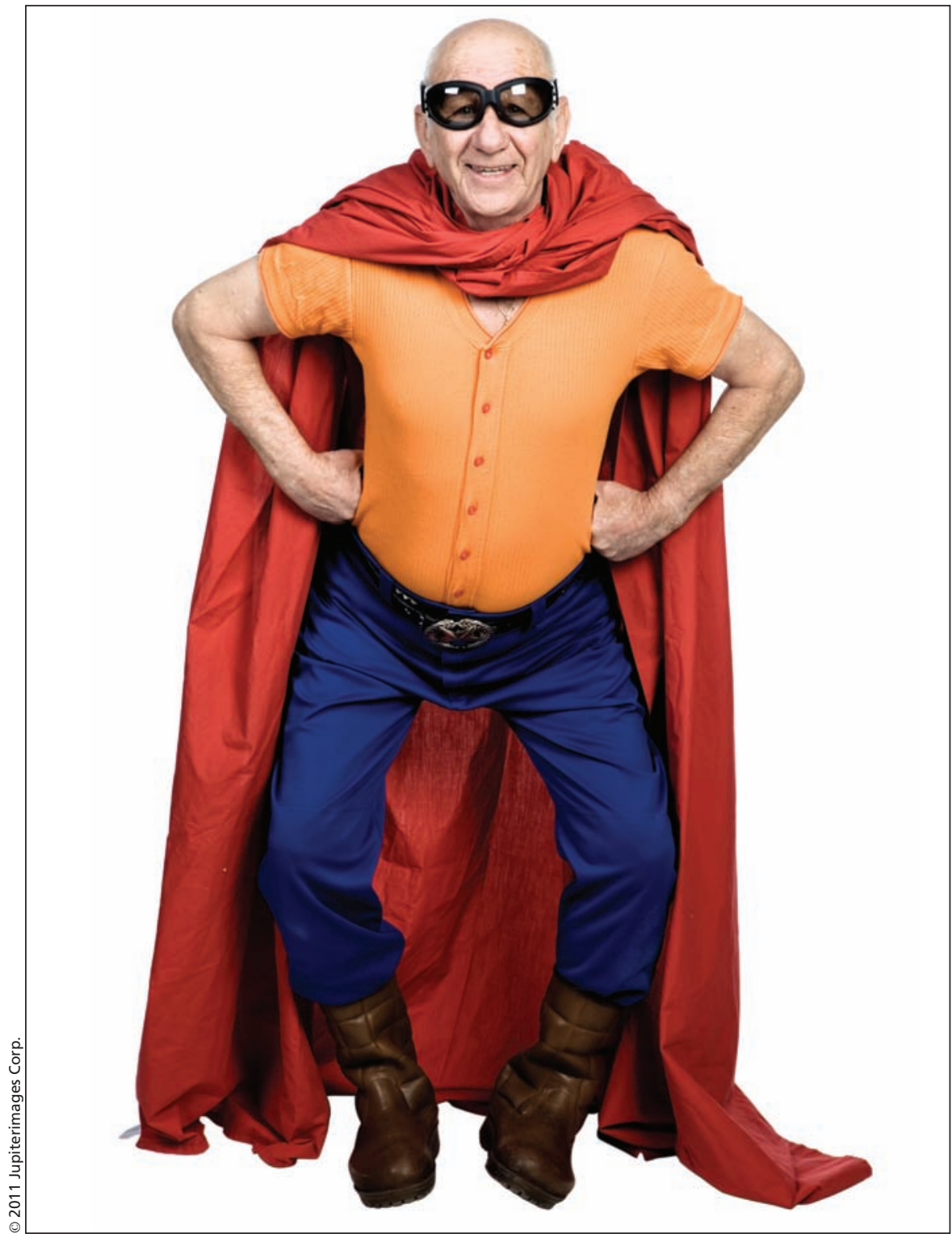

Finding someone with all of the qualities necessary to be an editor-in-chief-cum-superhero can be tricky.

and intellectual honesty. They must try to select material for its merit, interest to readers, and originality alone. They also want their journals to have a voice and a personality. If they are doing their jobs well, they should give no favors, and they should have no friends."

The editor of a medical journal must also be experienced in critically apprais- ing scientific articles, a skill that requires constant honing, says Smith, whose 13year term as editor of $B M J$ ended in 2004. Good writing and public speaking skills are also essential, as are creativity and boldness. "A sense of boldness and a thick skin are important," says Smith, now CEO of the European arm of UnitedHealth Group, a private US health 
care organization. "A journal sometimes has to speak truth to power and that's going to be uncomfortable."

One of an editor's most critical skills, if a medical journal is to be successful, is the ability to identify and nurture talent. "Any journal that can't be better than its editor is doomed," says Smith. "The way to make a good journal is to find good people and give them space to do interesting things."

In the United Kingdom, medical journals tend to pick editors from within cooperation and consensus are highly valued, and where command and control is not," Joshua Greenbaum, an industry analyst and head of Californiabased Enterprise Applications Consulting, writes in an email.

Still, corporate co-leadership remains somewhat of an enigma, working well under some circumstances and not so well under others, says Steven Dennis, Aarestad Chair of Banking in the College of Business \& Public Administration at the University of North Dakota.

\section{"Any journal that can't be better than its editor is doomed." - Dr. Richard Smith, former BMJ editor-in-chief.}

their ranks, or people who at least have experience working for a scientific journal. By contrast, journals in the United States have a tradition of awarding the top job to distinguished academics, says Smith. One European medical journal, Smith recalls, had a joint editorship model: one editor with a journal background to handle day-to-day operations, another with impressive academic credentials to set strategic directions. The model has also been successfully adopted by several specialty journals.

This is similar to the co-CEO model in the business world, which has been used by companies such as financial giants Charles Schwab and Citigroup, and also technology leaders Motorola and Research In Motion. "The co-CEO model can work in a culture where
"Co-CEOs that arise from co-founders seem to work very well and sometimes last for decades. Research in Motion, a Canadian company, has performed very well with co-CEOs," Dennis, the lead author of a paper exploring the co-CEO model (J Bus Econ Stud 2009;15:1-25), writes in an email. "Other co-CEO arrangements arise from mergers and acquisitions, and those tend not to last very long. Still other co-CEO arrangements arise from 'passing the torch' to two siblings, and the success of those relationships is sketchy at best."

Wherever hopeful editor-in-chief candidates spend the majority of their careers, it is important that they have a traceable - and successful — track record, says Dr. George Lundberg, editor-in-chief of the Journal of the Ameri- can Medical Association from 1982 to 1999. "The person should have name recognition in the medical community. It shouldn't be some dark horse who shows up unknown."

There are many other critically important characteristics that a person should possess to be considered for a position running a major international medical journal, says Lundberg, now editor-in-chief of Cancer Commons, which promotes using open science to help cancer patients tailor care to their needs (http://cancercommons.org). These characteristics include high intellect, broad medical knowledge, high ethical standards, sensitivity of the needs of journal staff, strategic planning skills, comfort with technology, a gift for public relations and a commitment to improving public health.

"Once an editor is chosen who has all these characteristics, this person must be willing to learn how to be an editor. They must be cautious and modest about their capacity to be successful on day one, and be willing to learn on the job," says Lundberg.

"It's a very complicated job, encompassing the whole field of medicine, as well as public health, ethics and also business, because money has to come from somewhere," adds Lundberg. "It is almost impossible to find someone who excels in all these areas. You find someone who has these qualities and excels in as many areas as possible." Roger Collier, CMAJ

CMAJ 2011. DOI:10.1503/cmaj.109-3785

\section{Orthotics work in mysterious ways}

$\mathrm{M}$ ost drivers don't think much about spark plugs and carburetors. They just want their vehicles to run, leaving the details to their mechanics. Most homeowners trust electricians to worry about voltages and alternating currents. They just want their lights to come on. In the same way, most patients who use medical devices just want the devices to work. Knowing how they work is the domain of clinicians and researchers. Unless, that is, the medical device is a foot orthotic.

According to Benno Nigg, professor of biomechanics and codirector of the Human Performance Laboratory at the University of Calgary in Alberta, even medical experts aren't sure exactly how orthotics relieve pain or prevent injury. "Orthotics can work and can have fantastic effects, but we don't know how they work," says Nigg.
The growing orthotics market could reach annual sales of US $\$ 4.7$ billion by 2015, according to Global Industry Analysts, Inc. (www.sfgate.com/cgi -bin/article.cgi?f=/g/a/2011/01/13/prweb 8061575.DTL). Orthotic devices are used by the public primarily to relieve pain, and by athletes to prevent injury. It is also a diverse business, including everything from custom products made from hightech materials to inexpensive insoles. 